\title{
Discussion of Application of Ecological Design Idea in Industrial Design
}

\author{
Yating Sun \\ Eastern International Art College \\ Zhengzhou University of Light Industry \\ Zhengzhou, China 450008
}

\begin{abstract}
The proposing of concept of ecological design has basis, which is a leap of present human's thought circle. From 1970s, harsh facts and rational thought made people aware of the importance of protecting environment and saving ecological balance, and the intercoordination and sustainable development between human and nature draw the attention of all the countries in the world. After suffering from environmental pollution and resource waste, while their material life was greatly satisfied, people started to desire safe, healthy life, desire to return to vivifying nature, desire safe portable products to satisfy the demand of daily life. Whether the designed works could truly return to nature and existed harmoniously with nature arose people's reflection of design, which was human's desire of life instinct, and the energysaving, effective, green, recyclable and reproducible ecological idea of sustainable development rose in response to the proper time and conditions.
\end{abstract}

Keywords - ecological design; industrial design; sustainable development; win-win result of economic development and environmental protection

\section{INTRODUCTION}

Ecological design, also called as green design or life cycle design, refers to bring environmental factors into design to help to decide the direction of strategy of design. The ecological design covers every aspect of human society, such as: ecological design of industrial production, ecological design of product development, ecological design of construction, ecological design of environment, and ecological design of humanity. The State Council officially approved "Statistical detection and assessment and execution scheme of energy conservation and emission reduction" in 2007.11, which clearly announced: from 2008, Chinese provincial officers shall submit result of energy conservation to the central government. In 2015.10, it was pointed out in the 5th plenary session of the 18th Central Committee that "sticks to green development, sticks to sustainable development, sticks to the road of ecological civilization development, and makes contribution to global ecological safety." This fully showed that propelling ecological design was imperative to China's industrial design.

Design is the front end of production and consumption, all the steps in the life cycle of industrial products are closely connected to the design idea of comprehensive designing ability of the designer. The ecological design requires to take environmental factors into account in all the stages of product development, reduce the influence on environment from the whole life cycle of the product, and finally lead to producing a more sustainable production and consumption system mode. The activities of ecological design mainly include connotation of two aspects: firstly is to reduce resource consumption, realize strategy of sustainable development from the aspect of environmental protection; secondly is to reduce cost and potential risk to improve competitiveness from the aspect of business. In fact, "ecological" design has become an imperative trend in the whole world, unprecedented huge changes have taken place from household appliance design, bathroom innovation, living space to public facility.

As a new subject, industrial design's enormous role in the modernization process of human is undisputed. From the industrial revolution, the world's economy has developed fast. The industrial design propels the modernization process of human along with industrial civilization. While enjoying material and civilization, people also pay heavy price of severely damaged existing environment. The industrial design brings convenient and comfortable life to people along with industrial civilization. However, people focus too much on design's effect on industry and economy and ignore the other aspects of design such as the value of nature, society, culture and art. For a long time, people are lost in the modern industrial civilization created by themselves, much negative influence of dual character of matters is covered by the achievement obtained, but the potential crises (global warming, sea level rising, global environmental pollution, resource and energy crises) and all kinds of social problems (rising of crime rate) have followed industrial civilization. Thus, improving human's existing environment, saving and cycling resource, building a society of sustainable development become an important topic of 21 st century. The coming of $21 \mathrm{st}$ century indicates that the awareness of ecological environment will guide the basic principle of people's life, and sustainable development of human society has become an urgent topic.

With human's development and society's progress, people have gradually realized that wholesome economy, rich society and good environment can not be separated with stability of society, and they started to explore how to solve 
the negative problems brought by industrial design. Thus, ideas of green design and ecological design aimed at improving human's existing environment, saving resource and cycling arose in 1970s. In recent years, a new word, "sustainable development" arose internationally, thinking about the issue of sustainability of human from two aspects of natural environment and sociality.

In industrial design, the design of traditional products are function oriented, mainly starting with meeting demand and solving problems, and consider little for ecological problems such as the resource consumption and influence on environment in later use of products. The ecological design idea focuses on environmental and ecological disruption caused by modern culture, overcoming the deficiency of traditional design, raising high claims on energy conservation and reduction of waste and material consumption, making the created industrial products meeting the requirements of human and environment and sustainable development. In 1968, an American designing theorist Victor Papanek published "Design for the real world", raising the finiteness and urgency of resource, advocating that design pay attention to environmental problems during designing and bear the responsibility to society and environment, however, at that time, all the countries were in the delight of rapid economic development brought by new technology, new material and new industrial design idea (such as the excellent design of UK), and didn't pay much attention to the warning of Victor Papanek and ignored the relation between design and environment. The rapid development of economy brought progress to human's material civilization, but caused long-range and irretrievable damage to the environment. In recent year, natural disasters like earthquake in Wenchuan and volcano in Iceland swept, and after suffering from environmental pollution and natural disasters, the designers no longer confined themselves to the exploration of the relations between product form and function, and human and product, and began to reflect the environmental problems caused by design. The ecological design idea became an important one to improve human's living environment and build sustainable development society, the article concludes adoption of the ecological design idea in industrial design via theory discussion and case analysis, the function of which represents in the following aspects in detail:

\section{The ECOLOGICAL DESIGN IDEA Is A DETAILED}

Practical Method OF Closely CONNECTING INDUSTRIal DESIGNING FIELD TO THE SOCIETY

In industrial design, applying the ecological design idea to design will further close the connection between the designer and society, making life the motivation of design. In the underway research of industrial design, the designers always get inspired from detailed social life. For example, teachers researching on industrial design in Zhengzhou Institute of Light Industry, Henan found that poor counties in Henan, Kaolan County and Ningling County are rich in white wax plant and paulownia during their research and investigation there, and they set up pragmatic cooperation with Bureau of Industrialization and Informatization of Kaolan, Ningling Ourui Artware Co., Ltd during field study and research to design and product industrial products made up of these two natural materials, see "Fig. 1", "Fig. 2" and "Fig. 3". People hope to promote local regional economy via design of industrial products, combine enterprises, education and research, promote the development of local special industries, and offer an innovative and developmental way for local economic development. The local natural resources of white wax plant and paulownia are abundant and reproducible, one the one hand, such selection of material satisfies the demand of sustainable development required by ecological design, on the other hand, such industrial production rarely pollute environment, and it promote the development of local sideline economy and improve people's income. The process of such design is the ecological design idea of ecological sustainable development itself, closely connecting design to practice while close designers' design to daily life, monitoring industrial design to get close to social daily life and leading it to a more humanistic development direction of design.

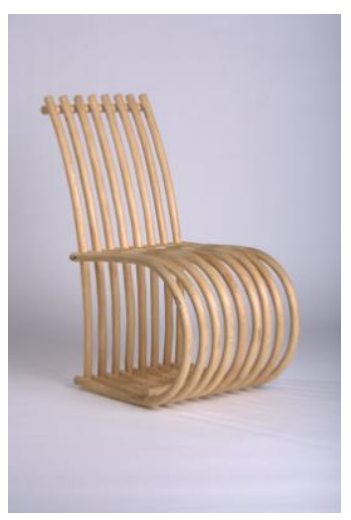

Fig. 1.

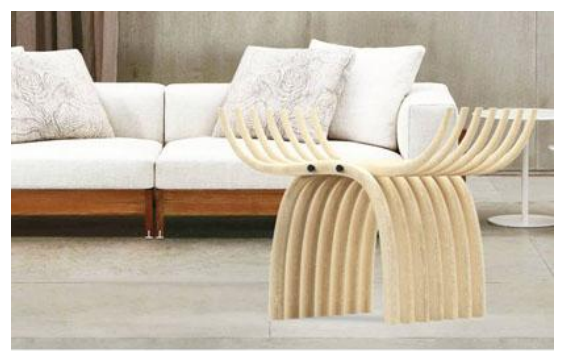

Fig. 2.

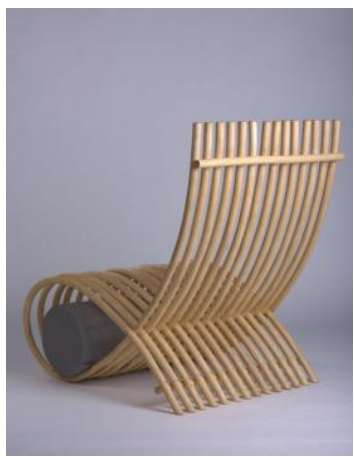

Fig. 3. 


\section{THE ECOLOGICAL DESIGN IDEA OFFERS SUPPORT TO SUSTAINABLE DEVELOPMENT DIRECTION OF INDUSTRIAL DESIGN}

In the "Eastern suburbs memory" theme park in Chenghua District, Chengdu, Sichuan, here was the former site of the former Chenghua Hongguang Electronic Tube Plant "Fig. 4". The abandoned former site of plant officially became national AAAA scenic spot via combination of update of urban industrial land and protection of industrial remains in 2013.7. The designer adopted the idea of sustainable development of ecological design to turn stuff like the old plant, equipment and machine part into designing elements "Fig. 5" and "Fig. 6". Besides, such design not only saved resource and cost, but also the reuse of old objects made people exclaim over and look back the past glorious history in the new combination of design, and nostalgia arose spontaneously. Such industrial design idea of ecological design was truly a good example, offering support to sustainable development direction of industrial design.

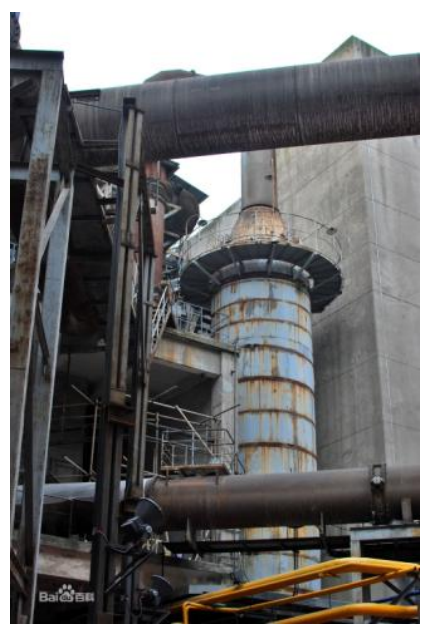

Fig. 4.

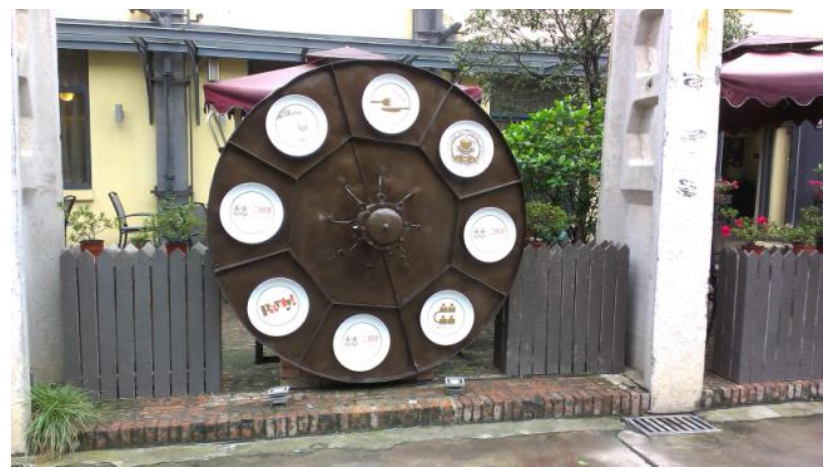

Fig. 5.

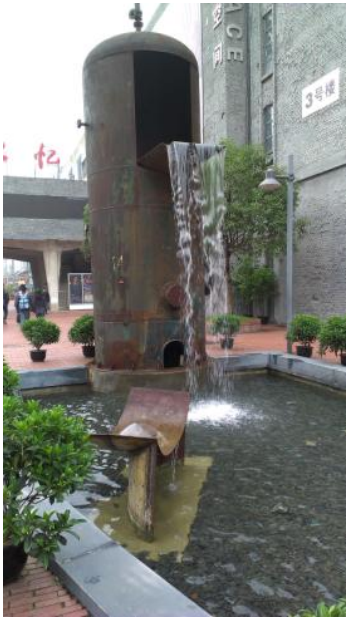

Fig. 6.

IV. THE FUSION OF ECOLOGICAL DESIGN IDEA OFFERS MORE ABUNDANT DESIGN IDEAS TO THE DEVELOPMENT OF INDUSTRIAL DESIGN

In industrial design, designing methods such as conceptual design, style design and bionics design always occupy people's mind. Designers are striving to make innovation of products while designing them. There is such a design organization called Artecnica Design Studio in LA, USA, whose designers have been exploring high-end design satisfying aesthetics and manufacture cost ever since it was founded, and one of its design standards is: economic feasibility. One of the ideas behind Artecnica is ecological design, and TransNeomatic "Fig.7" is a cushion made up of cycled tire and natural wickwicker. In Vietnam, dumped motor vehicle tires are everywhere, and there are also many craftsmen with excellent technology. The combination of Artecnica's idea of environmental protection and rich resources in Vietnam logically generates this type of cushion "Fig.8". Such design makes designers in Artecnica Design Studio win wide design space and more orders, and expand more abundant design ideas in the field of industrial design.

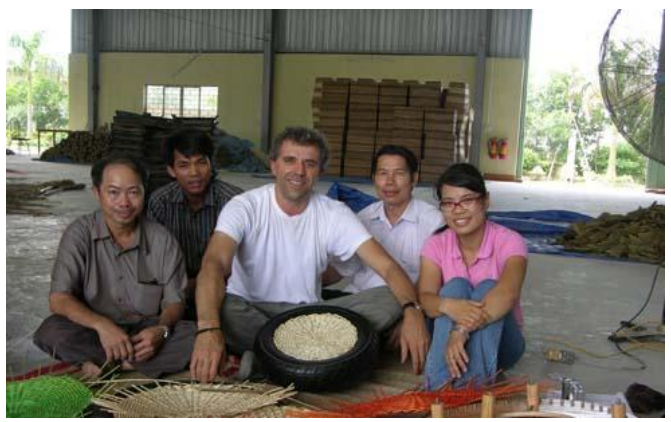

Fig. 7. 


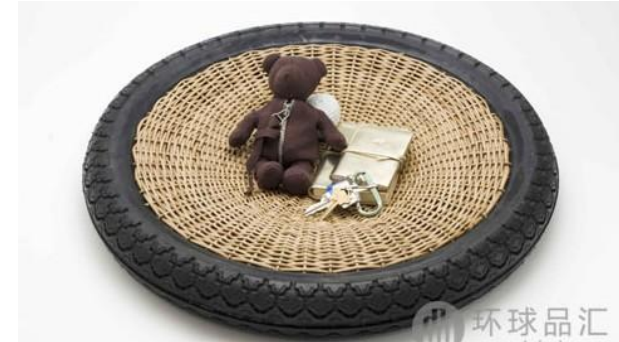

Fig. 8.

\section{To Promote ECOLOGICAL DESIGN IdEA WILL}

ACHIEVE WIN-W IN RESULT OF ECONOMIC DEVELOPMENT AND ENVIRONMENTAL SUSTAINABILITY

In the 21st century, how to face climate warming and ecological crisis is important to the whole planet, in the near future, there are bound to be more countries and international trade combo formulating more policies and setting access threshold in the aspects of encouraging to reduce environmental load and restricting non-green products. At present, China's industry is development fast while many environmental pollution problems arise, and haze in some first-tier and second-tier cities in China is proof of the damage to ecological environment. What our designers can do now is to start from the source of industrial design, focus on ecologicalization and sustainability of design, for example, the selection of raw material, simplification of processing mode and technology and sustainable use of material or part will all reduce cost of production. Such reusing method of resource will reduce consumption of production and thus reduce pollution to environment, and the ecological environment on which people depend to exist will be protected in some degree. The standardization of ecological design represents the general trend in western countries, and actually in early 1990s, "green purchase" had started to prevail in Japan, in late 1990s, there had been about $51 \%$ of Japanese enterprises executing green purchase. To enterprises, those who pay attention to ecological design first are easier to grab first chance in the market of green products and form a core advantage of competitiveness. Consumers will naturally advocate the strategies of ecological design and sustainable development after benefiting from products of ecological design, and thus a win-win result of economic development and environmental sustainability can be achieved. In cosmetics industry in South Korea, some brands adopt local orange peel as raw material for paper package, which is not only environmental protective but can also deepen consumers' impression of ecological design on this product, keeping good product image among consumers and achieving the win-win result of economic development and environmental sustainability of ecological design.

\section{CONCLUSION}

In conclusion, the ecological design idea has great influence on industrial design. Today it seems that both manufacturing industry and the society need a new direction, and design of ecological products may be a very good solution, which pushes designers of industrial products to the teeth of the storm, in the background global ecological environmental protection, and creates a new age of industrial design. At the same time, ecological design not only represents "green" and nonpollution to environment, which also includes sustainability of function, energy, economy and society, and it will be a large concept and category. The change of industrial designers will be revolutionary, which will contribute to ecologicalization and greenization of global environment, and greatly contribute to sustainable good development of earth environment where people live together.

\section{REFERENCES}

[1] [UK]Anne Chick, Sustainable Designing Revolution, Hu'nan University Press[M],2012.10, First edition

[2] [US]Farr. Sustainable Urbanization, Urban Design integrated with nature, China Architecture \& Building Press [M],2013.3, first edition

[3] [US] Xie Zhuofu, Design Reflection: strategy and practice of sustainable design, Tsinghua University Press[M], 2011.6, first edition

[4] Research on strategy of sustainable development of China's manufacturing industry,China Machine Press [M],2010.10, first edition

[5] Su Dagen, Zhong Mingfeng, Ecological Design of Material, Chemical Industry Press [M],2007.1, first edition

[6] Li Dehua, Ecological Design Science, Peking University Press [M],2012.11, first edition

[7] (GER) Nachtwey, Design Ecology!-Strategy of New Green Brand,Tianjin University Press [M],2010.1, first edition

[8] (EGY) Haiger,Sustainable Industrial Design and Waste Management, sustainable development "from cradle to cradle" , China Machine Press [M],2010.2, first edition

[9] (US) Xie Zhuofu, Design Reflection: strategy and practice of sustainable design, Tsinghua University Press[M],[M],2011.6, first edition

[10] (GER) Jörg Niemann (GER) Serge Tichkiewitch (GER) Engelbert Westkämper,Design of Sustainable Product Life Cycles, Beijing Institute of Technology Press [M],2015.8, first edition. 